\title{
El rol de la memoria colectiva y de la memoria individual en la conversión identitaria mapuche
}

Andrea Aravena R. ${ }^{1}$

\section{RESUMEN}

\begin{abstract}
A través de un estudio de casos con indígenas urbanos residentes en la ciudad de Santiago, proponemos analizar el rol de la memoria colectiva en el proceso de reconstrucción identitaria del mapuche urbano. Los residentes mapuche urbanos son miles de personas y sus experiencias, aún teniendo aspectos similares y compartidos, se dividen en múltiples fragmentos de acuerdo al género, la edad, la procedencia -rural o urbana-, el origen étnico de la familia, el lugar de acogida -la familia o el trabajo-, el lugar de residencia, las creencias, la posición social y económica. Sus memorias son múltiples y diversas, sin que ello impida la existencia de una memoria colectiva. Esta se expresa a través de la creencia y la reivindicación de un origen común y de la idealización de un pasado que los hace diferentes hacia el que los individuos se orientan, rememorando permanentemente la vida en comunidad y buscando el acercamiento a lo que ellos recuerdan como propiamente mapuche.
\end{abstract}

Palabras claves: identidad étnica - memoria colectiva lugares de memoria - indígenas urbanos.

\section{ABSTRACT}

As a result of research undertaken among the Mapuche community residing in Santiago city, this paper analyses the role that collective memory has in the reconstruction of urban Mapuche identity. Although sharing aspects in common, the urban experience of thousands of Mapuche is divided into multiple fragments along the lines of gender, age, origin -rural or urban-, the family's ethnic origin, the context of arrival to Santiago-family or work-, the place of residence, differences of creed and socio-economic positions. While their memories are multiple and diverse, this does not preclude the existence of a collective memory expressed in claims to -and beliefs in- a common origin, in the idealization of a past that both makes them different and shows them through the future, as well as in the permanent recalling of community life as a way to get closer to what they remember as being properly Mapuche.

Key words: ethnic identity - collective memories memory-place - urban indigenous.

Recibido: marzo 2004. Manuscrito revisado aceptado: junio 2004.

1 Fondo Nacional de la Discapacidad. Huérfanos $1313,6^{\circ}$ piso, Santiago, CHILE. Email: andrea.aravena@entelchile.net

\section{Presentación}

Los diferentes estudios contemporáneos realizados sobre la identidad étnica han demostrado que ésta puede ser observada y analizada al menos en tres niveles, respecto de los cuales puede tener implicaciones significativas en ciertas condiciones: el nivel microsocial o individual, el nivel mesosocial o grupal y el nivel macrosocial. A nivel individual, la etnicidad corresponde al sentimiento, a la conciencia de pertenencia que experimenta un individuo respecto de un determinado grupo étnico. A nivel grupal, la etnicidad corresponde principalmente a la movilización étnica y a la acción colectiva de carácter étnico. $\mathrm{Y}$ a nivel macrosocial o estructural, la etnicidad se ve involucrada por el conjunto de determinantes estructurales de naturaleza política, económica y social que moldea las identidades étnicas.

En este artículo, que resume los resultados parciales de una investigación sobre la identidad mapuche en los medios urbanos, analizaremos principalmente el comportamiento de la identidad étnica a nivel individual, tal como ella se manifiesta en los mapuche urbanos en Santiago y, en menor medida, a nivel grupal. Respecto de esta otra dimensión de la identidad étnica mapuche - el nivel grupal o mesosocial-y respecto del nivel estructural o macrosocial, consúltese otros trabajos de la autora. ${ }^{2}$

La hipótesis central a desarrollar en este trabajo es que la suma de "memorias individuales" de los mapuche urbanos de Santiago, así como su "memoria colectiva", juegan un rol central en el proceso de reconstrucción identitaria del mapuche urbano, contribuyendo a la formación de la identidad mapuche-warriache.

2 Específicamente para el análisis de los determinantes estructurales de la etnicidad mapuche urbana, consúltese: Aravena (2003 Ms). Para el análisis de la dimensión colectiva de la etnicidad mapuche urbana, consúltese: Aravena (1995a, 1995b, 1996, 1999, 2000, 2002). 


\section{El proceso de recomposición identitaria}

A nivel microsocial, ${ }^{3}$ en el proceso de inserción urbana y de adaptación cultural del mapuche migrante y en el proceso de adaptación cultural de los hijos de los migrantes, el "origen étnico" constituye la variable más importante. Dicha variable aparece en efecto como central, al momento de entrevistar a dirigentes mapuche urbanos sobre los determinantes de su identidad. Afirmada o negada, la identidad mapuche marca su existencia.

Sin embargo, llegar a asumir la identidad étnica mapuche como un rasgo identitario central pasa por un largo proceso en el que se observa un avance progresivo hacia la reconstrucción de la identidad mapuche urbana. Este proceso transita desde una situación inicial que puede ser de rechazo de la identidad de origen o familiar hasta la valorización de la identidad mapuche. Inicialmente, en efecto, el proceso de adaptación cultural al mundo urbano da lugar a un rechazo de la identidad y a una posterior afirmación identitaria. En un conjunto de entrevistas realizadas a mapuche migrantes y mapuche urbanos, constatamos que luego de un período en que la identidad de origen es cuestionada y, a veces, negada, aparece con más fuerza: "Mi identidad estaba dormida, me desperté"; "Es como si alguien me hubiese despertado, cuando me dijo es tu lugar, son tu gente y tu debes luchar por ellos. Fue como una especie de reencuentro con mi identidad"; "Yo reencontré mi identidad. La había perdido, es decir no la había perdido, pero ésta dormía en el fondo de mí”.

En el Cuadro 1, que resume los resultados de 12 entrevistas en profundidad, podemos constatar que el proceso de reconstrucción identitaria está motivado por un conjunto de razones. Para su descripción y análisis nos remitimos principalmente al nivel microsocial o individual de la etnicidad.

Como se dijo con anterioridad, en ciencias sociales el nivel microsocial de análisis de la etnicidad corresponde a una de las tres dimensiones o perspectivas desde las cuales observar y analizar la identidad étnica como fenómeno social. A este nivel, corresponde el análisis de las experiencias específicas y vivencias personales de los individuos respecto de una situación particular. Desde esa perspectiva, la etnicidad corresponde tanto al sentimiento como a la conciencia de pertenencia que experimenta un individuo respecto de un determinado grupo étnico.
Sólo en forma secundaria tratamos los niveles grupales y estructural, ya que no son el objeto de este trabajo.

Específicamente a nivel microsocial, la mayoría de las personas habla de una "elección personal", cuando la afirmación identitaria pasa por una decisión del individuo que elige asumir su identidad mapuche; por una "necesidad de redención del sufrimiento", cuando el individuo se rebela contra la discriminación de que ha sido objeto refugiándose en una reivindicación fundamentalista de la identidad, transformándose esta última en una suerte de reivindicación política y buscando su socialización; la "conversión religiosa", como medio de salir del estado de invisibilidad identitaria con la ayuda de una "fuerza divina o superior", claramente presente en el relato de un machi que residiendo en Santiago estaba enfermo, lo que lo lleva a decidir regresar a su comunidad para sanarse. En este viaje es iniciado como chamán y regresa a la ciudad sin los síntomas de su enfermedad y convertido en machi. En estas tres situaciones, adquieren importancia la influencia de la "memoria individual" y de la "memoria colectiva", en la afirmación de la identidad mapuche, cuando el individuo vive un proceso en el que el pasado individual en el seno de la familia o grupo de socialización primario y el pasado colectivo en el seno de la comunidad de origen adquieren una significación particular, siendo revalorizadas como experiencias.

A este nivel individual, por tanto, cabe señalar que el proceso de valorización identitaria comienza por "la necesidad de ser aceptado" como mapuche, asumiendo a la vez una "actitud crítica hacia la cultura huinca" y una suerte de "negación de la adscripción identitaria huinca". También, la "necesidad de ser aceptado" implica una "idealización de la vida en comunidad" con un interés especial por "salvaguardar los lazos con la cultura de origen" y, finalmente, un "deseo de reproducir la cultura comunitaria", lo que se hace a partir de la acción de la memoria, es decir, de la "memoria individual" y de la "memoria colectiva", como se analizará en la segunda parte de este trabajo.

Sólo a modo de referencia, diremos que en el mismo cuadro, pero a nivel macrosocial, se consigna el rol de la "acción o discriminación positiva" (medio social valorizante, subsidios económi- 


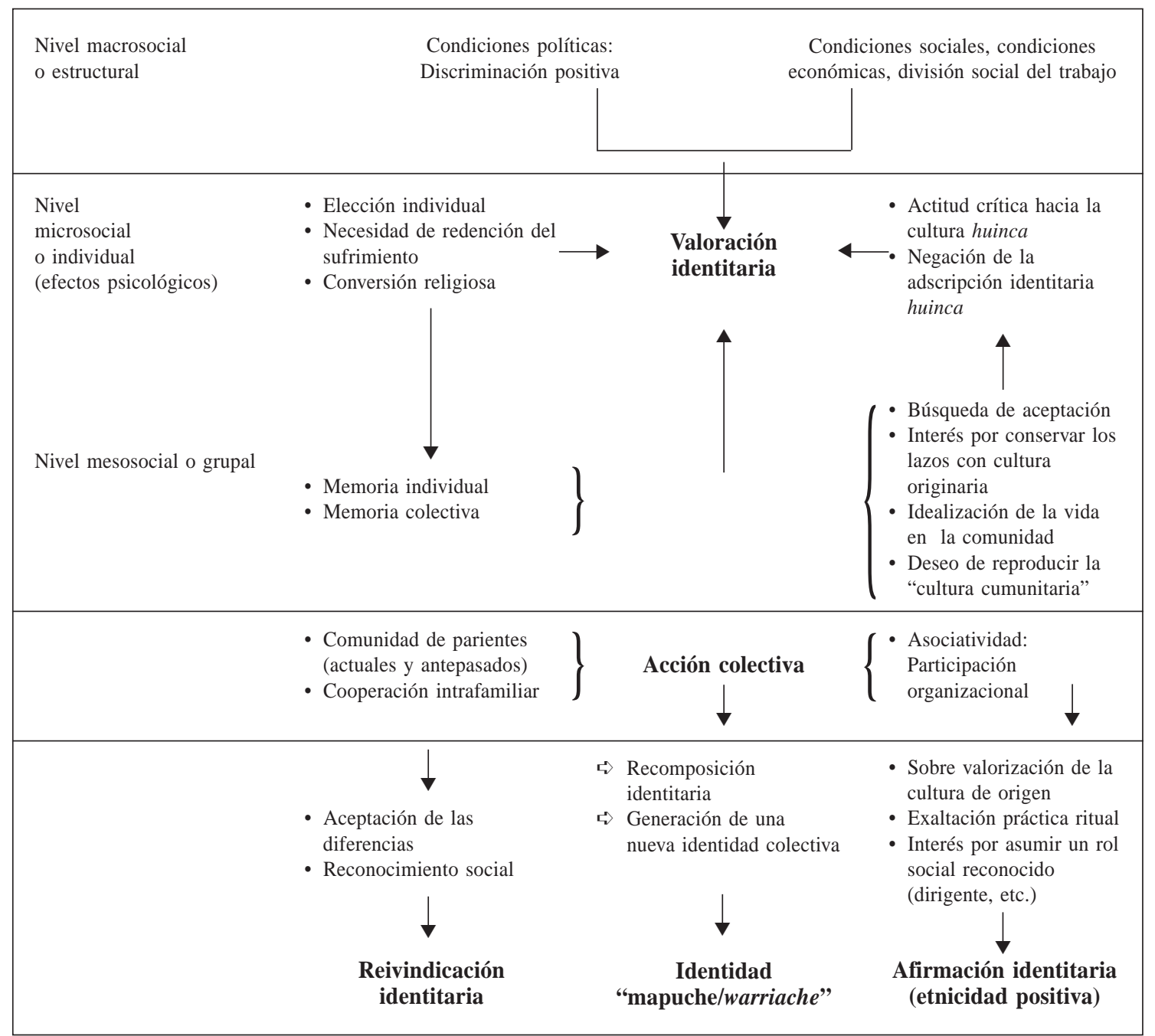

Cuadro 1. Proceso de recomposición de la identidad "mapuche-warriache" (Aravena 2002 Ms).

cos, apoyo político), que en el caso de nuestra investigación dice relación específica con la influencia de las políticas públicas en la decisión de asumir una identidad y particularmente la influencia de la acción de la Corporación Nacional de Desarrollo Indígena (CONADI) y otros servicios y programas públicos dirigidos a la población indígena (Aravena 2003 Ms).

En el mismo sentido podemos dimensionar, a nivel grupal, el rol de la comunidad de parientes y de la participación organizacional, como dos formas que asume la acción colectiva. En este plano, "la acción colectiva" puede darse a nivel de la "familia" o de la "organización". A nivel de la familia, se traduce en la "cooperación familiar" y en un interés por "salvaguardar los vínculos entre sî", con una aceptación de las diferencias y búsqueda de reconocimiento social. Esta relación de parentesco involucra no solamente a la familia nuclear sino a toda la comunidad de parientes y de ancestros; a nivel de la "organización", involucra un "interés asociativo" con semejantes, donde se manifiesta una "sobrevalorización de la cultura de origen", una "exaltación de la práctica ritual" y el "interés por asumir un nuevo rol social reconocido (de dirigente, chamán, profesor)" en el seno de esta organización. Como resultado último de este proceso se verifica una recomposición identitaria, con la afirmación de una identidad mapuche histórica y la reivindicación de una nueva identidad, la identidad "mapuche-warriache". En consecuencia, podemos afirmar que el nivel colectivo de la etnicidad está asociado a una experiencia grupal 
que conlleva una movilización étnica de los individuos, expresándose en un discurso reivindicativo asociado a una adscripción étnica y a una crítica de la sociedad no mapuche.

Las características o los "contenidos" de esta identidad "mapuche-warriache" son, sin lugar a dudas, la reivindicación misma de la identidad, pero también un conjunto de elementos tomados prestados de la cultura mapuche rural, y "amalgamados" por los citadinos. Este bricolage se hace a partir de la experiencia presente y de la memoria del pasado, particularmente la memoria colectiva. A continuación analizaremos precisamente el rol de las memorias individuales y de la memoria colectiva en el proceso de reconversión o reconstrucción identitaria mapuche en la ciudad.

\section{El rol de las memorias individuales y de la memoria colectiva}

Como ha sido señalado, el éxodo y la diáspora mapuche se caracterizan por su dispersión geográfica -el mapuche reside en todas las regiones del país-, por su urbanidad -el $80 \%$ se concentra en la Región Metropolitana- y por su masividad -afecta a miles de personas. De esta manera, los residentes mapuche urbanos son miles de personas y sus experiencias, aun teniendo aspectos similares y compartidos, se dividen en también múltiples fragmentos de acuerdo al género, la edad, la procedencia -rural o urbana-, el origen étnico de la familia, el lugar de acogida -la familia o el trabajo-, el lugar de residencia, las creencias, la posición social y económica. Sus memorias, por tanto, son múltiples y diversas, sin que ello impida la existencia de una memoria colectiva.

Cuando hablamos de identidad étnica debemos recordar la importancia de la memoria colectiva en el proceso de fijación de la identidad de los grupos étnicos, donde la creencia y la reivindicación de un origen común serían los elementos primordiales que permitirían a los individuos afirmar su identidad social y movilizar sus pertenencias étnicas. Como se ha dicho, lo que diferencia la identidad étnica de otras formas de identidades colectivas (religiosas o políticas) es que la identidad étnica se orienta hacia el pasado (Poutignat y Streiff-Fenart 1995: 177).

El término memoria colectiva, por su parte, aspira a dar cuenta de las formas de conciencia del pasado compartidas por un grupo social en el presente. Las memorias individuales se inscriben en el seno de la memoria colectiva de un grupo de pertenencia social primario, dice Halbwachs (1994 [1925]: 123). Aquí nos confrontamos a la doble dimensión de las memorias: aquella que resulta de la mirada del presente compartido hacia un pasado; y aquellas expresadas en el relato de cada individuo, que sorprenden por sus puntos en común más que por sus diferencias, confluyendo de esta manera hacia la existencia probable de una memoria colectiva. Ambas memorias se entrecruzan en el bricolage que hacen los individuos, como diría Lévi-Strauss.

A través de un estudio de casos con mapuche urbanos (Aravena 2002 Ms), hemos observado la manera en que aparece el rol de las memorias individuales y de la memoria colectiva en el proceso de reconstrucción identitaria del mapuche urbano, a través de: la creencia y la reivindicación de un origen común y de la idealización de un pasado que los hace diferentes hacia el que los individuos se orientan, rememorando permanentemente la vida en comunidad y buscando el acercamiento a lo que ellos recuerdan como propiamente mapuche:

"Nací en la comunidad mapuche de (...) a un costado del Océano Pacífico (...). Mi familia está compuesta por mis padres, mis tíos, mis primos y mis abuelos los que a la vez eran los integrantes de la comunidad en que vivía. Yo soy mapuche huilliche. Mis padres por todos lados eran mapuche. Mis bisabuelos y mis abuelos (...)".

“(...) Me siento orgullosa de ser mapuche, por que así me enseñaron en mi casa. Yo me siento superior en muchas cosas incluso, porque tengo una sabiduría que me viene de mi pueblo y que gracias a mi familia yo aprendí".

Lo que se considera como propiamente mapuche y que se busca revivir en la ciudad es el admapu o la tradición: el contacto con la naturaleza, con la tierra, con los ancestros, con el agua, la libertad de la vida rural, la abundancia de los alimentos, la vestimenta y las joyas, los instrumentos musicales, los bailes, las ceremonias, el rehue, la ruka, el fogón, las reuniones familiares, los juegos, los relatos orales y las figuras de los héroes históricos y de los espíritus de los antepasados, como una especie de hitos fundadores de su iden- 
tidad, por citar los más emblemáticos: "Yo nací hace mucho tiempo, (...), en la comunidad, en la tierra, en la casa, alrededor del fuego, donde nacieron todos mis hermanos".

“(...) Yo fui educada con identidad, mi padre, mi abuela siempre me dijeron que ser mapuche era más bonito que ser huinca, ser mapuche es valioso, me decían 'no cualquiera puede ser mapuche'. (...) Así que yo crecí con el orgullo de ser mapuche”.

Pero la memoria es también selectiva; ello significa que en el proceso de significación de acontecimientos los actores privilegian algunos hechos, descartándose o relegándose otros. En los hitos que ellos recuerdan, y que constituyen parte de los que los mapuche llaman el admapu -hacer o producir lo que quiere la tierra, el mandato de la tierra, ley tradicional de la tierra mapuche-, se privilegian las bondades de la vida en familia, los recuerdos de la naturaleza y de la vida en la comunidad, las enseñanza recibida de los familiares o antepasados sobre el valor de ser mapuche y, especial valor se le asigna a las ceremonias tradicionales, además de otros elementos tradicionales, como la ruka o el rehue, que se constituyen en elementos de significación en las prácticas mapuche urbanas.

“(...) cada cierto tiempo yo me voy al sur, allá nos reunimos con mi mamá, con mi familia en torno al fuego y hablamos de la tierra, de los sueños, de la historia. Ese es nuestro alimento, lo que nos da fuerzas para hacer las cosas que hacemos acá. Además allá llevo a las niñas, que nunca terminan de aprender y bueno, uno tampoco. De allá sacamos la fuerza de ser mapuche, que es lo primero que somos, mapuche".

Como sabemos, sin embargo, la memoria no es sólo individual ni autobiográfica, sino también colectiva, ya que los individuos comparten espacios que generan recuerdos compartidos, capaces de transformarse en un discurso social de grupo. Igualmente, sabemos que este proceso de conformación de la memoria colectiva no es un fenómeno ahistórico, sino que tiene lugar en el presente, de manera selectiva, en ciertos lugares o espacios que se vuelven simbólicos. Recordemos a Pierre Nora, quien retomando las tesis de Halbwachs nos habla de aquellas "unidades significativas", de orden material o ideal sobre las que la voluntad de los hombres o el trabajo del tiempo hizo un elemento simbólico de una cierta comunidad, lo que él llama los "lugares de memoria" (Nora 1997). Con anterioridad, Bastide (1964, 1968, 1970) habló de la existencia de estructuras materiales organizacionales como el receptáculo de la memoria colectiva, entregando pistas muy interesantes sobre la existencia de tales lugares de expresión de la memoria colectiva, como son el baile, el mito, el rito. Así el mito, el rito, la religión o la organización podrían ser lugares simbólicos de la memoria. La diferencia fundamental a precisar respecto a Bastide es que esos lugares no deben ser entendidos, de ninguna manera, como simples receptáculos de la memoria, pero sí como contexto. Y en tal medida, podrían constituir espacios de reproducción y de construcción de la identidad. Como tal, la memoria colectiva no solamente sería reproductora sino también productora, y su invocación no solamente permitiría reproducir ciertas formas de identidad sino también producir nuevas formas de identidad, o recrear. Se trata en última instancia de la apropiación de diversos espacios o lugares de memoria que constituyen el fundamento identitario de la identidad mapuche-warriache en Santiago.

A través de nuestro estudio de casos, descubrimos también que en el caso de los mapuche en Santiago existían al menos tres lugares o "cuadros sociales" de la memoria mapuche, como puede verse en los ejemplos citados: la familia entendida como sistema de parentesco y por extensión, la comunidad; la organización; y la religión, a través de sus prácticas. En el contexto urbano, en efecto, a fuerza de recuerdos, los mapuche conservan su emblemática herencia, la de aquella cultura reduccional, de la comunidad. En los relatos revisados, la mantención de la identidad comunitaria es una lucha constante contra el sufrimiento de vivir "enajenado" y contra el olvido, de la que resulta una búsqueda incansable de las circunstancias que permitan revivir esa identidad comunitaria.

"Yo sentía ese sufrimiento y quería reunir a los hermanos, pero no sabía como hacerlo (...), y mientras impulsaba mi triciclo me decía que había que empezar a organizarse y luego comenzamos a juntarnos (...)".

"En esa organización nuestro objetivo era recordar todo eso, recordar nuestras tradiciones, (...) reunirnos para no perder nuestras costumbres". "Ahí cantamos, bailamos, fabricamos nuestra vestimenta, 
cocinamos y también hacemos ceremonias, es decir todo lo que sentimos como mapuche".

Podríamos decir que los mapuche-warriache viven así sumergidos en un sueño permanente que los aproxima a la cultura ancestral, fortaleciendo su identidad mapuche urbana. En sus recuerdos se encuentra inmersa su identidad, aproximándose a los recuerdos de la vida familiar y a la voluntad de otorgarles vigencia en la práctica y actualización de esos recuerdos. Aún en el caso de los hijos de migrantes, que no obstante no haber vivido la experiencia comunitaria ni de familia extendida en la comunidad rural, han heredado de sus padres los contenidos memoriales de esta vida en comunidad, haciendo su propio bricolage de experiencias, apropiándose de elementos relatados por sus padres y finalmente constituyéndolos en una memoria que es fundamento de su identidad. Se trata de una vida familiar y por extensión -comunitaria-, que no se constituye en la ciudad, ya que la familia extendida propia del mundo rural no resulta funcional a la vida familiar nuclear del mundo urbano. Sin embargo, en la memoria individual subyace el recuerdo de la experiencia colectiva, experiencia que es por tanto buscada en el seno de las organizaciones. En forma análoga, los integrantes de la organización son aceptados como miembros de la familia. "Formar parte de una asociación mapuche urbana es lo mismo que formar parte de una comunidad". "Las mujeres [de la organización] son parte de nuestra familia".

Por último, entre los recuerdos más fuertes de la "cosmovisión" mapuche, las fiestas y ceremonias tradicionales ocupan un lugar particular, como si a través de la religiosidad el mapuche urbano pudiera viajar a través de la historia.

"Yo viví solamente cuatro años en la comunidad. Sin embargo guardé mis recuerdos (...). Por ejemplo, cuando me llevaban a los nguillatunes, $o(\ldots)$ las ceremonias funerarias, los casamientos (...), lo que me llamaba la atención eran los viejos que cantaban en la ruka de mi abuela; siempre me preguntaré qué es lo que cantaban y nunca olvidaré la melodía de esas canciones. (...). Me recuerdo de los nguillatunes, del sabor del muday, sabor que seguía sintiendo en Santiago".

La identidad mapuche-warriache es en este aspecto la resignificación del pasado mapuche y la domesticación del presente urbano, una síntesis del ideal comunitario dejado en el pasado con las adaptaciones propias que impone el mundo urbano. Pareciera que "cultura rural" y "cultura urbana" se encuentran en un proceso de actualización de la memoria colectiva, a través del bricolage de ambas que hacen los individuos. La memoria colectiva, inspirada en el pasado, se actualiza en el presente, proyectándose al futuro como la base constitutiva de una nueva identidad. Así las memorias individuales se consolidan en un discurso social de grupo étnico en el presente.

\section{Conclusiones}

En trabajos anteriores hemos sostenido que la identidad étnica no puede ser definida por un conjunto de características físicas, psicológicas y culturales objetivas. Pero sí por la construcción social y política de tales características, permitiendo la diferenciación de grupos denominados étnicos (Aravena 2000, 2001, 2002, 2002 Ms). Desde un punto de vista subjetivo, el sentimiento de pertenencia étnica y el hecho de compartir una herencia cultural común (Barth 1976 [1969]; Leach 1968; Poutignat y Streiff-Fenart 1995) parecieran ser los principales criterios de definición de los grupos étnicos como categoría de diferenciación social. Desde esta perspectiva, la etnicidad es considerada como una forma de organización social capaz de constituirse y de transformarse en la interacción de los grupos sociales, designando así los procesos a través de los cuales los individuos se identifican y son identificados por otros, atribuyéndose identidades particulares, sin permanecer atados a una entidad fija definida desde el exterior (Barth 1976 [1969]: 10).

Ser mapuche en Santiago reviste sin duda una dimensión ampliamente subjetiva. Desde un punto de vista individual y microsocial, ser mapuche en Santiago corresponde justamente al "sentimiento", a la "conciencia de pertenencia que manifiesta el individuo en relación a su grupo étnico" y "a la manera en como ellos se identifican en último término y en cómo son identificados por los huincas". El proceso de diferenciación de los mapuche de los no mapuche se da en un contexto de relaciones no recíprocas y de desigualdades sociales y económicas, donde estereotipos étnicos y estereotipos sociales se acercan y aproximan. El mapuche citadino se reconstruye como tal a pesar del contexto de "conflicto étnico", a lo lar- 
go de un proceso de subvaloración y de discriminación que enfrenta en el medio urbano.

En el proceso de identificación a la identidad mapuche, las memorias individuales y colectivas juegan un papel central. El mapuche-warriache pertenece a un conjunto de individuos que comparte una comunidad de origen, herencia que a su vez transmiten a sus hijos y que les permite identificarse a una cultura mapuche. Al principio, niegan su adscripción a la identidad mapuche y es posible que a veces nazcan desprovistos de esta identidad en términos objetivos. Por el contrario, su identidad es el resultado de un proceso dinámico de construcción individual y social. En este proceso, las memorias individuales y su cristalización en una memoria colectiva mapuche, aun llena de los buenos recuerdos de la vida en la comunidad, en ninguna medida se queda estancada en el pasado. Por el contrario, ésta demuestra su dinamismo y su capacidad constante de ser reelaborada, inscribiéndose en la temporalidad del presente y en el espacio de la residencia urbana.

A través de sus memorias individuales, la experiencia mapuche-warriache demuestra la capaci- dad de los mapuche de sobreponerse a las circunstancias adversas que enfrentan en su vida cotidiana, a través de la resignificación de la identidad. Apoyados en los recuerdos de la comunidad, los mapuche-warriache enarbolan su proyecto histórico otorgando continuidad histórica a su residencia urbana. Sus recuerdos individuales y sus memorias colectivas grupales son revividos en determinados lugares o "contextos sociales", como diría Halbwachs: la familia, la organización, las ceremonias religiosas. Rememorar no es revivir, pero es reconstituir un pasado a partir de los contextos sociales del presente (Halbwachs 1994 [1925]).

La memoria colectiva constituye así un lugar por excelencia de expresión y de transmisión de la identidad colectiva mapuche, corroborándose la importancia de la memoria colectiva en la fijación de la identidad étnica de los grupos étnicos. Finalmente, la memoria colectiva mapuche no solamente sería reproductora sino también productora, y su invocación no solamente permitiría reproducir ciertas formas de identidad sino también producir nuevas formas de identidad, o recrear, como es el caso de la identidad mapuchewarriache.

\section{REFERENCIAS CITADAS}

ARAVENA, A., 1995a. Las etnias en la ciudad. Revista Enfoques Año 9, 1: 6-10.

_ 1995b. Desarrollo y procesos identitarios en el mundo indígena urbano. En Publicación del Departamento de Biología Celular y Genética de la Facultad de Medicina de la Universidad de Chile, pp. 35-50, Santiago, y en Publicación del Instituto de Estudios Indígenas de la Universidad de la Frontera, pp. 171-178, Temuco.

_ 1996. Modernité, ethnicité et migration: La question de l'identité chez les mapuches de Santiago du Chili. Memoria de Diplome d'Etudes Approfondies, en "Antropología y Sociología Política”, Universidades de Paris VIII y París I (IEDES), Paris.

1999. La identidad indígena en los medios urbanos: Una reflexión teórica a partir de los actuales procesos de recomposición de la identidad étnica mapuche en la ciudad de Santiago. En Actas del Tercer Congreso Chileno de Antropología, pp. 460-470. Temuco, 1998.

2000. La identidad indígena en los medios urbanos: Una reflexión teórica a partir de los actuales procesos de recomposición de la identidad étnica mapuche en la ciudad de Santiago. En Lógica mestiza en América, Instituto de
Estudios Indígenas de la Universidad de la Frontera, Temuco.

-2002 Ms. Mapuches en Santiago. Memorias de inmigrantes y residentes. Texto mimeografiado.

—-2002. Los mapuche-warriache: Procesos migratorios contemporáneos e identidad mapuche urbana. En Colonizacion, resistencia y mestizaje en las Américas, varios autores, Abya-Yala, Quito / Instituto Francés de Estudios Andinos, Lima.

-2003 Ms. Reconocimiento jurídico, políticas de desarrollo y etnicidad en Chile: El rol de las políticas públicas en el discurso étnico. Comunicación presentada en el Simposio Multiculturalidad, Derechos y Etnicidad, $51^{\circ}$ Congreso Internacional de Americanistas, Universidad de Chile, Santiago.

BARTH, F., 1976 [1969]. Introducción. En Los grupos étnicos y sus fronteras. La organización social de las diferencias culturales. Fondo de Cultura Económica, México D. F.

BASTIDE, R., 1964. Ethnologie des capitales latino-américaines. Caravelle, Extrait des cahiers du monde hispanique et luso-brésilien, pp. 73-89. Bibliothèque de la Maison des Sciences de l'Homme, París. 
ANDREA ARAVENA R.

1968. Psychologie et ethnologie. En Ethnologie générale. La Pléiade, Gallimard, París.

-1970. Mémoire collective et sociologie du bricolage. L'année Sociologique, III è série, pp. 37-48. PUF, París.

HALBWACHS, M., 1994 [1925]. Les cadres sociaux de la mémoire. Albin Michel, París.
LEACH, E., 1968. Critique de l'Anthropologie. PUF, París.

NORA, P., 1997. Les lieux de mémoire. P. Nora (Coord.). Gallimard, París.

POUTIGNAT, P. y J. STREIFF-FENART, 1995. Théories de l'ethnicité. Presses Universitaires de France, París. 